\title{
Steady State Power Flow Analysis of Unified Power Quality Conditioner (UPQC)
}

\author{
Vinod Khadkikar ${ }^{1}$, A. Chandra ${ }^{1}$, A. O. Barry ${ }^{2}$ and T. D. Nguyen ${ }^{3}$ \\ e-mail : v_khadkikar@yahoo.com, chandra@ele.etsmtl.ca
}

\begin{abstract}
This paper deals with the steady state analysis of unified power quality conditioner (UPQC). The UPQC, a combination of shunt and series active power filter (APF), is one of the best solutions towards the mitigation of voltage sags and swells problems on distribution network. The analysis is based on active and reactive power flow through the shunt and series APF, wherein series APF can absorb or deliver the active power whereas the reactive power requirement is totally handle by shunt APF alone during all conditions. This analysis is very useful for selection of kVA ratings for both shunt and series APF. The MATLAB / SIMULINK results are provided in order to verify the analysis.
\end{abstract}

Key words-- Active Power Filter (APF), UPQC, Voltage Sag, Voltage Swell, Power Quality, SPS MATLAB / SIMULINK.

\section{INTRODUCTION}

$\mathrm{D}$ ue to the extensive use of power electronic based equipments/loads almost in all areas, the point of common coupling (PCC) could be highly distorted [1][3]. Also, the switching ON/OFF of high rated load connected to PCC may result into voltage sags or swells on the PCC. There are several sensitive loads, such as computer or microprocessor based AC/DC drive controller, with good voltage profile requirement; can function improperly or sometime can lose valuable data or in certain cases get damaged due to these voltage sag and swell conditions.

One of the effective approaches is to use a unified power quality conditioner (UPQC) at PCC to protect the sensitive loads. A UPQC is a combination of shunt and series APFs, sharing a common dc link [1-3], [6-10]. It is a versatile device that can compensate almost all power quality problems such as voltage harmonics, voltage unbalance, voltage flickers, voltage sags \& swells, current harmonics, current unbalance, reactive current, etc.

Recently more attention is being paid on mitigation of voltage sags and swells using UPQC [6-10]. The swells are not as common as sags, but the effects of a swell can be more destructive than sag. For example, the excessive overvoltage

The authors would like to thank Natural Sciences and Engineering Research Council of Canada (NSERC) and IREQ / Hydro-Québec for providing financial support for this research work.

${ }^{1}$ Vinod Khadkikar and A. Chandra are with Département de génie électrique, École de Technologie Supérieure, Montréal, Canada.

${ }^{2}$ A. O. Barry is with Laboratoire de simulation de Réseaux, IREQ, Varenne, Canada.

${ }^{3}$ T. D. Nguyen is with Secteur Industriel et qualité du service électrique, Hydro Québec, Montréal, Canada. during swell condition may cause breakdown of components or equipments. The common cause of voltage sag and swell is sudden change of line current flowing through the source impedance.

This article is based on the steady state analysis of UPQC during voltage sag and swells on the system. Aim is to maintain the load bus voltage sinusoidal and at desired constant level in all operating conditions. The major concern is the flow of active and reactive power during these conditions, as it plays an important role in selecting the kVA ratings of both shunt and series APF.

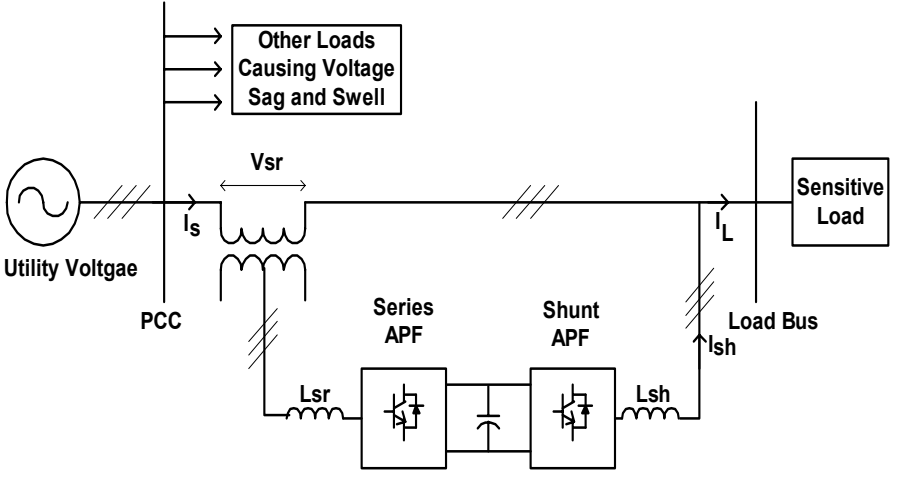

Fig. 1 Block Diagram of UPQC

The system configuration under consideration is discussed in section II. The steady state power flow analysis is discussed in the section III. The SIMPOWERSYSTEM (SPS) Matlab / Simulink based simulation results are discussed in section IV and finally section $\mathrm{V}$ concludes the paper.

\section{SYSTEM CONFIGURATION}

Fig.1 shows a system configuration for UPQC. The voltage at PCC may be or may not be distorted depending on the other non-linear loads connected at PCC. Also, these loads may impose the voltage sag or swell condition during their switching ON and/or OFF operation. The UPQC is installed in order to protect a sensitive load from all disturbances. It consists of two voltage source inverters connected back to back, sharing a common dc link. One inverter is connected parallel with the load. It acts as shunt APF, helps in compensating load harmonic current, reactive current and maintain the dc link voltage at constant level. The second inverter is connected in series with the line using series transformers, acts as a controlled voltage source maintaining the load voltage sinusoidal and at desired constant voltage level. 


\section{STEADY-STATE POWER FLOW ANALYSIS}

The powers due to harmonics quantities are negligible as compared to the power at fundamental component, therefore, the harmonic power is neglected and the steady state operating analysis is done on the basis of fundamental frequency component only. The UPQC is controlled in such a way that the voltage at load bus is always sinusoidal and at desired magnitude. Therefore the voltage injected by series APF must be equal to the difference between the supply voltage and the ideal load voltage. Thus the series APF acts as controlled voltage source. The function of shunt APF is to maintain the dc link voltage at constant level. In addition to this the shunt APF provides the var required by the load, such that the input power factor will be unity and only fundamental active power will be supplied by the source.

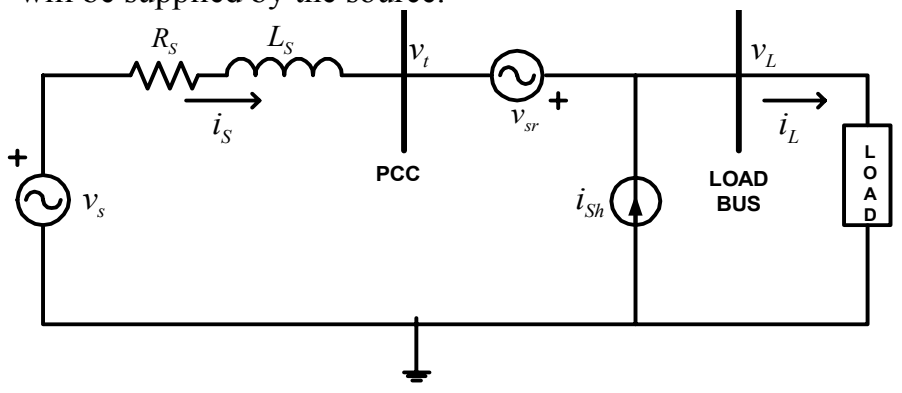

Fig. 2 Equivalent Circuit of a UPQC

The voltage injected by series APF can vary from $0^{0}$ to $360^{\circ}$. Depending on the voltage injected by series APF, there can be a phase angle difference between the load voltage and the source voltage. However, in changing the voltage phase angle of series APF, the amplitude of voltage injected can increase, thus increasing the required $\mathrm{kVA}$ rating of series APF [7].

In the following analysis the load voltage is assumed to be in phase with terminal voltage even during voltage sag and swell condition. This is done by injecting the series voltage in phase or out of phase with respective to the source voltage during voltage sag and swell condition respectively. This suggests the real power flow through the series APF. The voltage injected by series APF could be positive or negative, depending on the source voltage magnitude, absorbing or supplying the real power. In this particular condition, the series APF could not handle reactive power and the load reactive power is supplied by shunt APF alone. The single phase equivalent circuit for a UPQC is shown in the Fig. 2. The source voltage, terminal voltage at PCC and load voltage are denoted by $\mathrm{v}_{\mathrm{S}}, \mathrm{v}_{\mathrm{t}}$ and $\mathrm{v}_{\mathrm{L}}$ respectively. The source and load currents are denoted by $i_{S}$ and $i_{L}$ respectively. The voltage injected by series APF is denoted by $v_{S r}$, where as the current injected by shunt APF is denoted by $i_{S h}$.

Taking the load voltage, $v_{L}$, as a reference phasor and suppose the lagging power factor of the load is $\operatorname{Cos} \phi_{L}$ then we can write;

$$
\bar{v}_{L}=v_{L}<0^{0}
$$

$$
\begin{aligned}
& \bar{i}_{L}=i_{L} \angle-\phi_{L} \\
& \bar{v}_{t}=v_{L}(1+k) \angle 0^{0}
\end{aligned}
$$

Where factor $k$ represents the fluctuation of source voltage, defined as,

$$
k=\frac{v_{t}-v_{L}}{v_{L}}
$$

The voltage injected by series APF must be equal to,

$$
\bar{v}_{S r}=\bar{v}_{L}-\bar{v}_{t}=-k v_{L} \angle 0^{0}
$$

The UPQC is assumed to be lossless and therefore, the active power demanded by the load is equal to the active power input at PCC. The UPQC provides a nearly unity power factor source current, therefore, for a given load condition the input active power at PCC can be expressed by the following equations,

$$
\begin{aligned}
& p_{t}=p_{L} \\
& v_{t} \cdot i_{S}=v_{L} \cdot i_{L} \cdot \operatorname{Cos} \phi_{L} \\
& v_{L}(1+k) \cdot i_{S}=v_{L} \cdot i_{L} \cdot \operatorname{Cos} \phi_{L} \\
& i_{S}=\frac{i_{L}}{1+k} \cdot \operatorname{Cos} \phi_{L}
\end{aligned}
$$

The above equation suggests that the source current $i_{S}$ depends on the factor $k$, since $\phi_{L}$ and $i_{L}$ are load characteristics and are constant for a particular type of load.

The complex power absorbed by the series APF can be expressed as,

$$
\begin{aligned}
& \bar{S}_{S r}=\bar{v}_{S r} \cdot i_{S}^{*} \\
& P_{S r}=v_{S r} \cdot i_{S} \cdot \operatorname{Cos} \phi_{S}=-k \cdot v_{L} \cdot i_{S} \cdot \operatorname{Cos} \phi_{S} \\
& Q_{S r}=v_{S r} \cdot i_{S} \cdot \operatorname{Sin} \phi_{S}
\end{aligned}
$$

$\phi_{S}=0$, since UPQC is maintaining unity power factor

$$
\begin{aligned}
& P_{S r}=v_{S r} \cdot i_{S}=-k \cdot v_{L} \cdot i_{S} \\
& Q_{S r} \cong 0
\end{aligned}
$$

The complex power absorbed by the shunt APF can be expressed as,

$$
\bar{S}_{S h}=\bar{v}_{L} \cdot i_{S h}^{*}
$$

The current provided by the shunt APF, is the difference between the input source current and the load current, which includes the load harmonics current and the reactive current. Therefore, we can write;

$$
\begin{aligned}
\bar{i}_{S h} & =\bar{i}_{S}-\bar{i}_{L} \\
\bar{i}_{S h} & =i_{S} \angle 0^{0}-i_{L} \angle-\phi_{L} \\
\bar{i}_{S h} & =i_{S}-\left(i_{L} \cdot \operatorname{Cos} \phi_{L}-j i_{L} \cdot \operatorname{Sin} \phi_{L}\right) \\
\bar{i}_{S h} & =\left(i_{S}-i_{L} \cdot \operatorname{Cos} \phi_{L}\right)+j i_{L} \cdot \operatorname{Sin} \phi_{L} \\
\therefore \quad P_{S h} & =v_{L} \cdot i_{S h} \cdot \operatorname{Cos} \phi_{s h} \\
& =v_{L} \cdot\left(i_{S}-i_{L} \cdot \operatorname{Cos} \phi_{L}\right) \\
Q_{S h} & =v_{L} \cdot i_{S h} \cdot \operatorname{Sin} \phi_{s h}=v_{L} \cdot i_{L} \cdot \operatorname{Sin} \phi_{L}
\end{aligned}
$$




\section{CASE I:}

The reactive power flow during the normal working condition when UPQC is not connected in the circuit is shown in the Fig. 3 a). In this condition the reactive power required by the load is completely supplied by the source only. When the UPQC is connected in the network and the shunt APF is put into the operation, the reactive power required by the load is now provided by the shunt APF alone; such that no reactive power burden is put on the mains. So as long as the shunt APF is $\mathrm{ON}$, it is handling all the reactive power even during voltage sag, voltage swell and voltage harmonic compensation. As discussed above the series APF is not taking any active part in supplying the load reactive power. The reactive power flow during the entire operation of UPQC is shown in the Fig. 3 b).

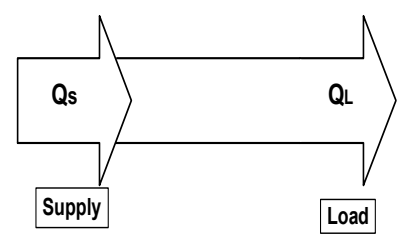

a) No UPQC

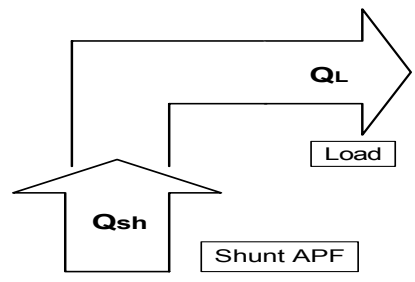

b) With Shunt APF
Fig. 3 a) - b) Reactive Power Flow

\section{CASE II:}

If $k<0$, i.e. $v_{t}<v_{L}$, then from equation (4) and (13), $P_{S r}$ will be positive, means series APF supplies the active power to the load. This condition is possible during the utility voltage sag condition. From equation (9), $i_{S}$ will be more than the normal rated current. Thus we can say that the required active power is taken from the utility itself by taking more current so as to maintain the power balance in the network and to keep the dc link voltage at desired level.

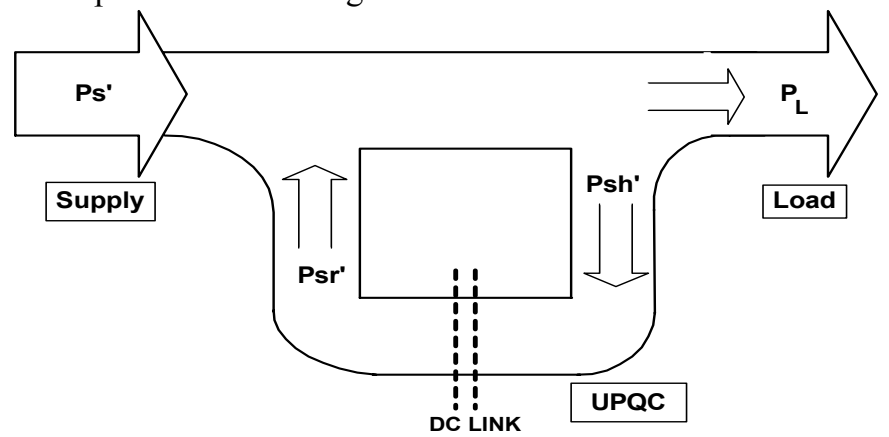

Ps'= Power Supplied by the source to the load during voltage sag condition Psr' = Power Injected by Series APF in such way that sum Psr'+Ps' will be the required load power during normal working condition i.e. PL Psh'= Power absorbed by shunt APF during voltage sag condition Psr' $=$ Psh'

Fig. 4 Active Power Flow during Voltage Sag Condition

This active power flows from the source to shunt APF, from shunt APF to series APF via de link and finally from series APF to the load. Thus the load would get the desired power even during voltage sag condition. Therefore in such cases the active power absorbed by shunt APF from the source is equal to the active power supplied by the series APF to the load. The overall active power flow is shown in Fig. 4.

\section{CASE III:}

If $k>0$, i.e. $v_{t}>v_{L}$, then by equation (4) and (13), $P_{S r}$ will be negative, this means series APF is absorbing the extra real power from the source. This is possible during the voltage swell condition. Again by equation (9), $i_{S}$ will be less than the normal rated current. Since $v_{S}$ is increased, the de link voltage can increase. To maintain the dc link voltage at constant level the shunt APF controller reduces the current drawn from the supply. In other words we can say that the UPQC feeds back the extra power to the supply system. The overall active power flow is shown in Fig. 5.

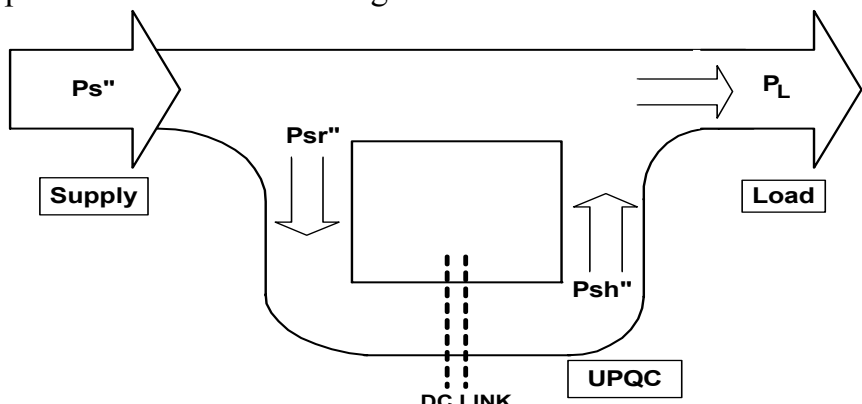

Ps"= Power Supplied by the source to the load during voltage swell condition Psr"= Power Injected by Series APF in such way that sum Ps"-Psr" will be the required load power during normal working condition

Psh"= Power delivered by shunt APF during voltage sag condition

Psr" $=$ Psh"

Fig. 5. Active Power Flow during Voltage Swell Condition

\section{CASE IV:}

If $k=0$, i.e. $v_{t}=v_{L}$, then there will not be any real power exchange though UPQC. This is the normal operating condition. The overall active power flow is shown in Fig. 6.

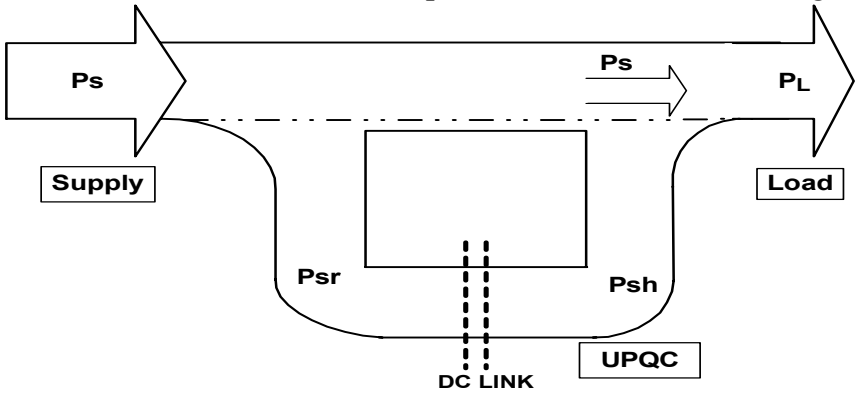

Fig. 6. Active Power Flow during Normal Working Condition

The phasor representations of the above discussed conditions are shown in the Fig. 7 (a) - (d). Phasor 7 (a) represents the normal working condition, considering load voltage $v_{L}$ as a reference phasor. $\phi_{L}$ is lagging power factor angle of the load. During this condition $i_{S}$ will be exactly equal to the $i_{L}$ since no compensation is provided. When shunt APF is put into the operation, it supplies the required load vars by injecting the leading current such that the source 
current will be in phase with the terminal voltage. The phasor representing this is shown in Fig. 7 (b). The phasor representations during voltage sag and voltage swell condition on the system are shown in the Fig. 7 (c) and Fig. 7 (d) respectively.

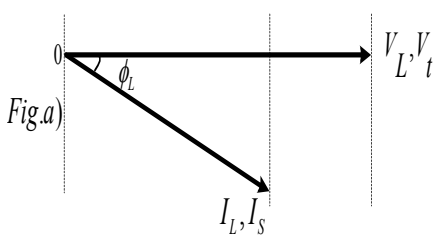

Normal working Condition, without any compensation

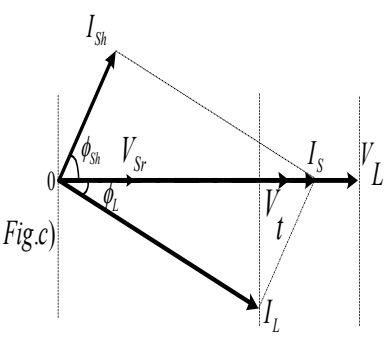

UPQC ON, Voltage Sag

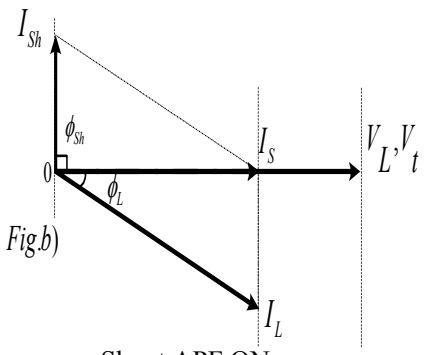

Shunt APF ON

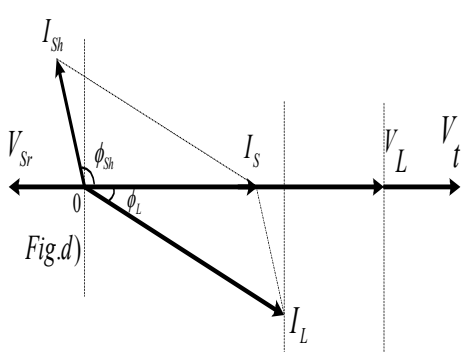

UPQC ON, Voltage Swell
Fig. 7 a) -d) Phasor Representation of all Possible Conditions

In normal operating condition, the shunt APF provides the load vars, whereas, series APF handles no active or reactive power, so in this case the rating of series APF would be small fraction of load rating. The shunt APF rating mainly depends on the compensating current provided by it, which depends on the load power factor or load var requirement. Lower the load power factor higher would be the shunt APF rating. From equations (4), (9) and (13), the series APF rating depends on two factors, source current $i_{S}$ and factor $k$. The current $i_{S}$ increases during voltage sag condition where as decreases during voltage swell condition. Therefore the rating of series APF is considerably affected by the $\%$ of sag need to be compensated. A compromise needs to be made while considering the series APF ratings, which directly affects the sag compensation capability of UPQC. Depending on the load requirement an optimisation can be done on these two issues. The shunt APF rating would increase slightly while considering $\%$ sag and $\%$ swell compensation since it has to maintain the dc link voltage.

\section{SIMULATION RESULTS}

The performance of the UPQC under the steady state conditions have been verified by computer simulation. The SIMPOWERSYSTEM blockset of MATLAB / SIMULINK have been used as a simulation tool. The control algorithm is based on unit vector templates generation [3]. The three phase terminal voltages, three phase load voltages, three phase source currents and the dc link voltage are sensed and used to generate the switching patterns for shunt and series APFs. The overall control circuit is shown in the Fig. 8. To analyse the performance of UPQC during voltage sag and swell conditions, the voltage at PCC is assumed to be pure sinusoidal, where as, a R-L load is considered as a sensitive load to be protected. The simulation results are shown in the Fig. 9 and Fig. 10.

There are four instants; $\mathrm{t} 1, \mathrm{t} 2, \mathrm{t} 3$ and $\mathrm{t} 4$. Before time $\mathrm{t} 1$, the source current is same as the load current, which is 0.85 lagging the source voltage. At time $t 1=0.1 \mathrm{sec}$, the shunt APF is put into the operation. The reference dc link voltage is set at $220 \mathrm{~V} \mathrm{dc}$. The shunt APF controller acts immediately forcing dc link voltage to settle down at new steady state value i.e. at $220 \mathrm{~V}$. This is done by taking the fundamental input current from the source and within two cycles of input the dc link voltage is maintained at constant level, as shown in the Fig. 9 (d). The shunt APF injects a leading compensating current and

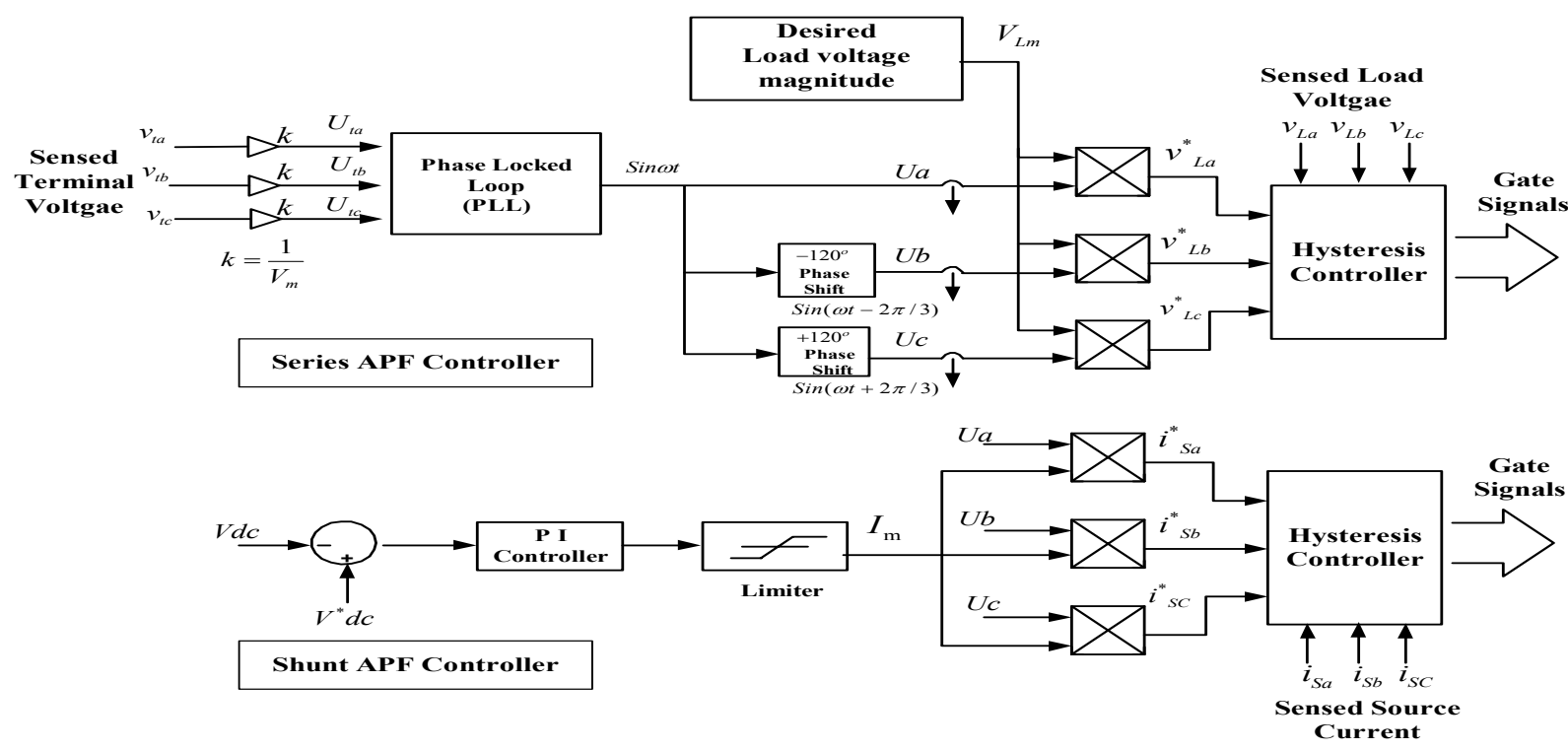

Fig. 8 UPQC Controller based on Unit Vector Templates Generations 
supplies the load vars, making the input power close to unity. Here the power factor is improved from 0.857 lagging to 0.998. The source current waveform and the shunt compensating current waveform are shown in Fig. 9 (e) and Fig. 9 (g) respectively.
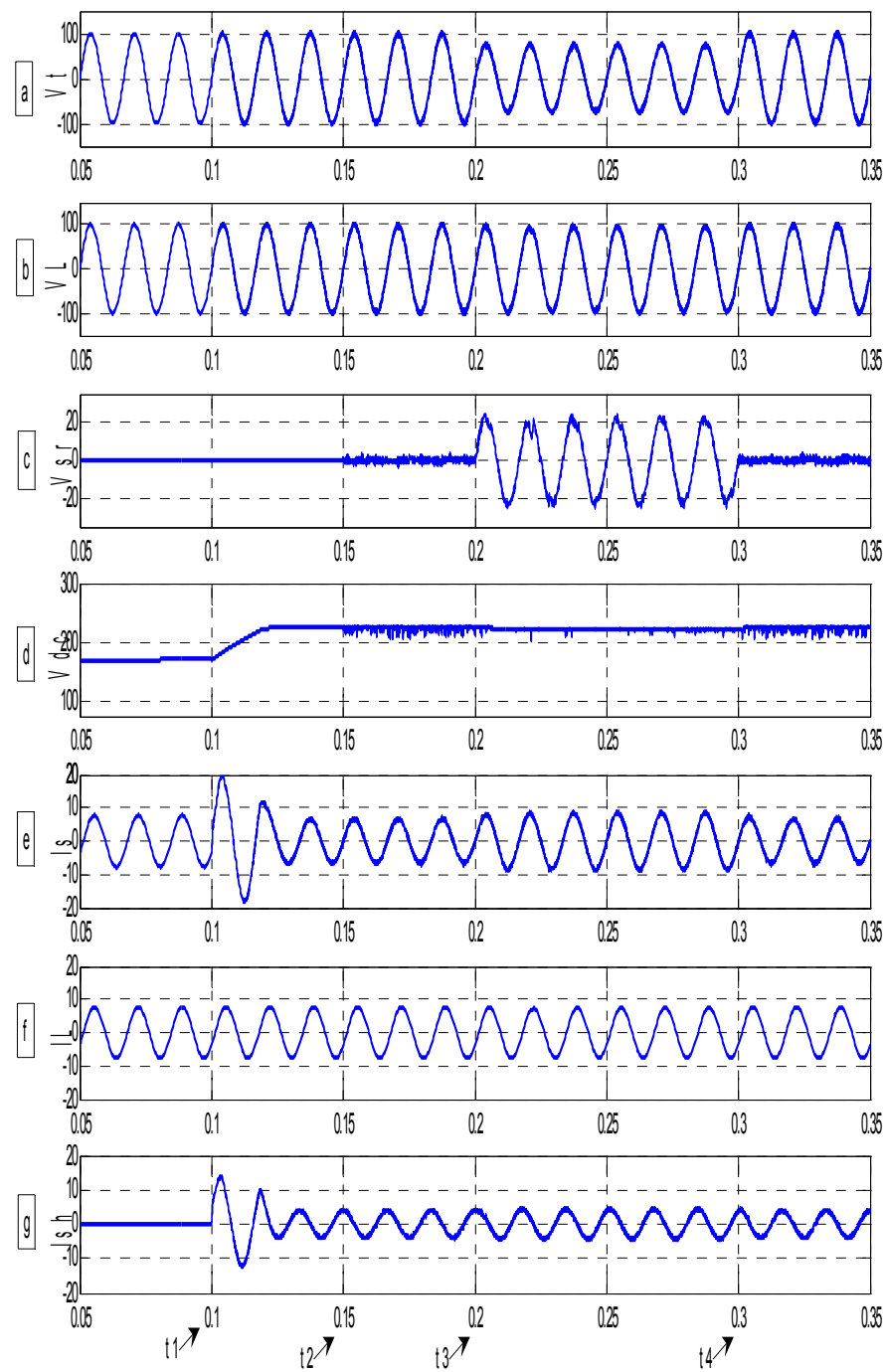

Fig. 9 (a)-(g) UPQC: Voltage Sag Compensation

At time t $2=0.15 \mathrm{sec}$, series APF is put into operation such that both series and shunt APFs are operating together as UPQC. At time $t 3=0.2 \mathrm{sec}$, a sag (25\%) is introduced on the system, this sag lasted till time $t 4=0.3 \mathrm{sec}$, as shown in the Fig. 9 (a). After time $t 4=0.3 \mathrm{sec}$, the system is again at normal working condition. During the voltage sag condition, the series APF is providing the required power of the load by injecting in phase compensating voltage $(25 \%)$ equals to the difference between the reference load voltage and source voltage, as shown in the Fig. 9 (c). The load voltage profile shown in the Fig. 9 (b), shows that UPQC is maintaining it at desired constant level even during the sag on the system such that load bus is free from the sag voltage variation. While series APF is providing the required real power to the load, the shunt APF is maintaining the dc link voltage at constant level such that the series APF can provide the needed real power to the load. To maintain the dc link voltage at constant level the source delivered more current. Here the source current magnitude is increased from $6.63 \mathrm{~A}$ to $8.51 \mathrm{~A}$; as shown in Fig. 9 (e). In other words, the required load power is provided by the source only, by delivering more current. This extra power flows from source to shunt APF, shunt APF to series APF via dc link and from series APF to the load, but without any delay in the operation.

Now a swell (25\%) is introduced on the system during the time $\mathrm{t} 3=0.2 \mathrm{sec}$ to $\mathrm{t} 4=0.3 \mathrm{sec}$, as shown in the Fig. 10 . Under this condition the series APF is absorbing the extra real power from the source by injecting an out of phase compensating voltage $(25 \%)$ in the line through series transformers, as shown in the Fig. 10 (c). The load voltage profile in the Fig. 10 (b) shows the UPQC is effectively maintaining the load bus voltage at desired constant level. The UPQC controller acts in such a way that source delivers the reduced current, as shown in Fig. 10 (e). Here the source current magnitude
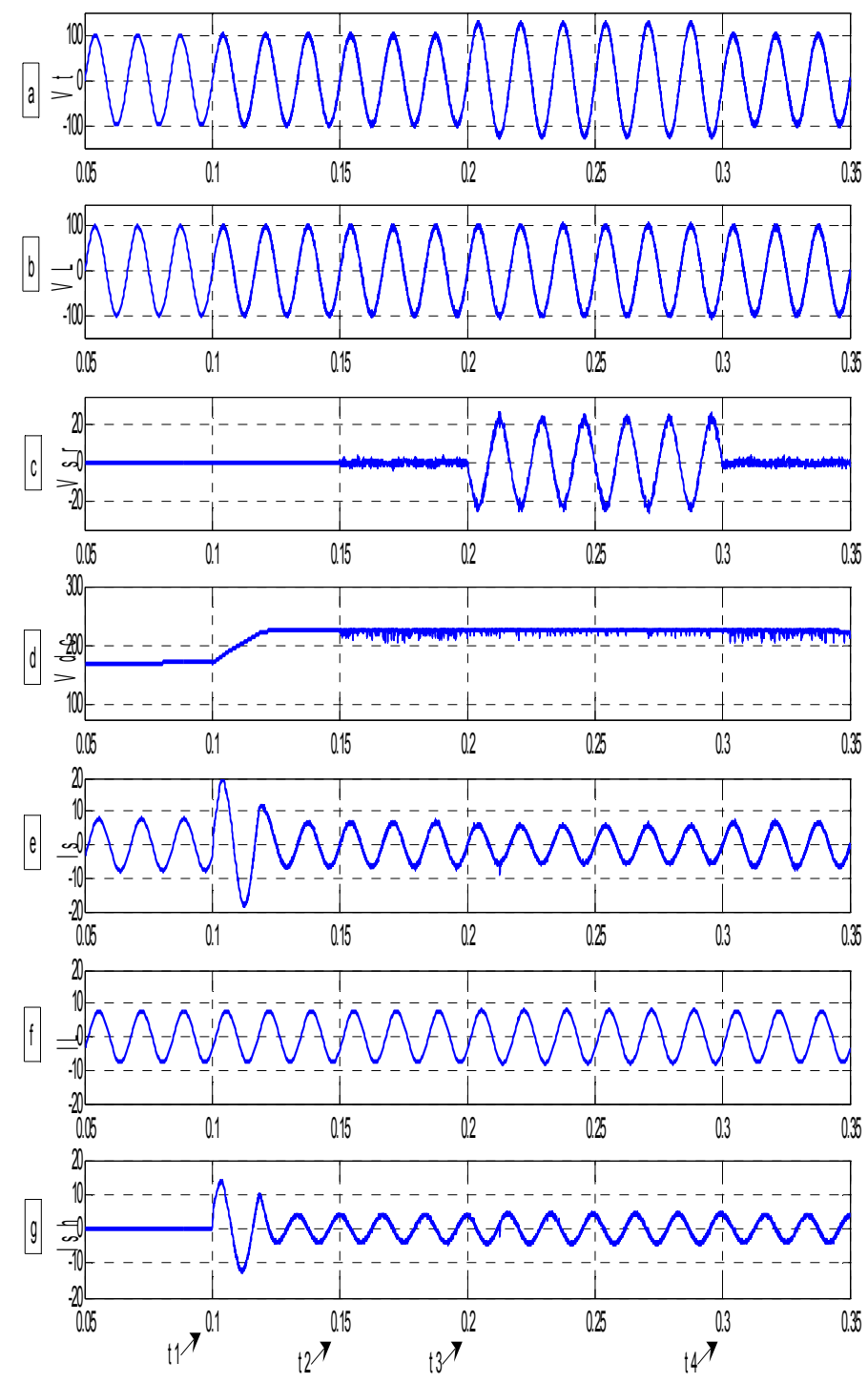

Fig. 10 (a)-(g) UPQC: Voltage Swell Compensation 
decreases from $6.63 \mathrm{~A}$ to $5.57 \mathrm{~A}$. In other words the extra power due to the voltage swell condition is fed back to the source by taking reduced fundamental source current. The shunt APF maintains the dc link voltage at constant level.

Table I shows the effect of load var requirement on the $\mathrm{kVA}$ ratings of both shunt and series APFs. The kVA ratings are mentioned on the basis of $\%$ of load kVA rating. For a fixed load active power $(\mathrm{P}=1000 \mathrm{w})$, the var required by the load varied and a swell of $25 \%$ is imposed on the system.

Table I ( $\mathrm{P}=1000 \mathrm{w}$ at $25 \%$ Swell)

\begin{tabular}{|c|c|c|c|c|c|}
\hline \multirow{2}{*}{$\begin{array}{c}\text { Sr. } \\
\text { No. }\end{array}$} & \multirow{2}{*}{ Load kVA } & \multicolumn{2}{|c|}{ Normal Condition ( No Sag/Swell) } & \multicolumn{2}{c|}{ During Swell Condition } \\
\cline { 3 - 6 } & & Shunt APF kVA & Series APF kVA & Shunt APF kVA & Series APF kVA \\
\hline 1 & $1.02(\mathrm{Q}=200$ vars $)$ & $19.6 \%$ & $\cong 0$ & $27.45 \%$ & $18.13 \%$ \\
\hline 2 & $1.166(\mathrm{Q}=600$ vars $)$ & $51.88 \%$ & $\cong 0$ & $57.9 \%$ & $15.86 \%$ \\
\hline 3 & $1.414(\mathrm{Q}=1000$ vars $)$ & $70.72 \%$ & $\cong 0$ & $75.67 \%$ & $13.08 \%$ \\
\hline
\end{tabular}

Table II ( $\mathrm{P}=1000 \mathrm{w}$ and $\mathrm{Q}=600$ vars $)$

\begin{tabular}{|c|c|c|c|c|c|}
\hline \multirow{2}{*}{$\begin{array}{c}\text { Sr. } \\
\text { No. }\end{array}$} & \multirow{2}{*}{$\%$ of Swell } & \multicolumn{2}{|c|}{ Normal Condition ( No Sag/Swell) } & \multicolumn{2}{c|}{ During Swell Condition } \\
\cline { 3 - 6 } & & Shunt APF kVA & Series APF kVA & Shunt APF kVA & Series APF kVA \\
\hline 1 & $20 \%$ & $51.45 \%$ & $\cong 0$ & $54.88 \%$ & $13.29 \%$ \\
\hline 2 & $25 \%$ & $51.88 \%$ & $\cong 0$ & $57.90 \%$ & $15.86 \%$ \\
\hline 3 & $30 \%$ & $52.23 \%$ & $\cong 0$ & $60.89 \%$ & $18.86 \%$ \\
\hline
\end{tabular}

From table I, as load var requirement increases the $\mathrm{kVA}$ rating of shunt APF increases significantly. On the other side the $\mathrm{kVA}$ rating of series APF decreases as the total $\mathrm{kVA}$ rating of the load is increased. Table II shows the effect of \% swell on kVA ratings of both APFs. For a fixed load, as $\%$ of swell compensation increases, the kVA rating of series increases accordingly. The kVA rating of shunt APF during the swell condition increases slightly to maintain the dc link as discussed previously.

\section{CONCLUSION}

A steady state power flow analysis of UPQC is presented in this paper. The Matlab / Simulink based simulation is done in order to verify the analysis proposed. The series APF injects in phase voltage during voltage sag condition and out of phase voltage during voltage swell condition and maintains the voltage at load bus at desired constant level. The shunt APF helps series APF during voltage sag and swell condition by maintaining the de link voltage at set constant level, such that series APF could effectively supply or absorb the active power. In addition to this shunt APF also provides the required load vars and thus making the input power factor close to unity. This analysis is very useful in selection of kVA ratings of both series and shunt APFs depending on the $\%$ of sag and swell needed to be compensated.

\section{REFERENCES}

[1] H. Akagi, "New trends in active filters for improving power quality", Proceedings of the 1996 International Confe, Vol.1, Jan 1996, pp. $417-425$.

[2] B. Singh, K. Al-Haddad, A. Chandra, "A Review of Active Power Filters for Power Quality Improvement", IEEE Trans on Industrial Electronics, Vol. 45, No.5, Oct1999, pp. 960-071.
[3] Khadkikar V, Agarwal P, Chandra A, Barry A O and Nguyen T.D, "A simple new control technique for unified power quality conditioner (UPQC)", Harmonics and Quality of Power, 2004. 11th International Conference on 1215 Sept. 2004, pp. $289-293$.

[4] A. Chandra, B. Singh, B.N. Singh, K. Al-Haddad, "An Improved Control Algorithm of Shunt Active Filter for Voltage Regulation, Harmonic Elimination, Power Factor Correction, and Balancing of Nonlinear Loads", IEEE Trans on Power Electronics, Vol. 15, No. 3, May 2000, pp.495-507.

[5] M T Tsai, "Analysis and design of a cost-effective series connected AC voltage regulator", IEE Proc. Electr. Power Appl., Vol. 151, No. 1, Jan 2004, pp. 107-114.

[6] Muthu, S.; Kim, J.M.S, "Steady-state operating characteristics of unified active power filters." Applied Power Electronics Conference and Exposition, 1997. APEC ' 97 Conference Proceedings 1997, Twelfth Annual, Volume: 1, 23-27 Feb 1997, pp. 199 -205.

[7] Li R.; Johns A T. and Elkateb M.M., "Control concept of Unified Power Line Conditioner." Power Engineering Society Winter Meeting, 2000. IEEE, Volume:4 , 23-27 Jan 2000, pp. 2594 -2599.

[8] Elnady A and Salama M.M.A., "New functionalities of the unified power quality conditioner." Transmission and Distribution Conference and Exposition, 2001 IEEE/PES, Volume: 1, 28 Oct.-2 Nov 2001, pp. 415 -420.

[9] Basu M, Das S.P. and Dubey G.K., "Performance study of UPQC-Q for load compensation and voltage sag mitigation." IECON 02, IEEE, Volume: 1, 5-8 Nov 2002, pp. $698-703$.

[10] Ghosh A, Jindal A.K. and Joshi A., "A unified power quality conditioner for voltage regulation of critical load bus", Power Engineering Society General Meeting, 2004. IEEE 6-10 June 2004, pp. 471 - 476.

\section{BIOGRAPHIES}

Vinod Khadkiar was born at Aurangabad (MH, INDIA) in 1978. He received his Bachelor of Engineering and Master of Technology degrees in Electrical Engineering from Dr. B.A.M University, Aurangabad and IIT Delhi in 2000 and 2002, respectively. Presently he is pursuing his Doctor of Engineering degree in the Department of Electrical Engineering, École de Technologie Supérieure, Montréal, CANADA. His research interests are Application of Power Electronics in Distribution Systems, Power Quality Analysis, Active Power Filters, etc.

Ambrish Chandra (SM'99) was born in India in 1955. He received B.E. degree from the University of Roorkee, India, M. Tech. degree form I.I.T., New Delhi, India, and Ph.D. degree from University of Calgary, Canada, in 1977, 1980, and 1987, respectively.

He worked as a Lecturer and later as a Reader at University of Roorkee. Since 1994 he is working as a Professor in Electrical Engineering Department at École de technologie supérieure, University of Québec, Montreal, Canada. His main research interests are power quality, active filters, static reactive power compensation, and flexible AC transmission systems (FACTS). Dr. Chandra is a senior member of IEEE and member of the Order of Engineers of Quebec, Canada.

Alpha Oumar Barry was born in Republic of Guinea in 1956. He graduated from Université Laval in 1982, where he received the B. S. in Electrical Engineering and a M. S. in Power Electronics at Université du Québec à Trois-Rivières in 1985.

Since 1984, he is with the Institute de Recherche d'Hydro-Québec (IREQ). From 1984 to 1988, he worked with the Research Group in the area of wind generation, dealing with system problems in motor control and power electronics as applied to aerogenerators. His current research area is in power system simulation including real-time digital models interfaced with analog simulator. He is member of Ordre des Ingénieurs du Québec.

T. D. Nguyen graduated from École Polytechnique, Montréal, in 1977. Since then he is working as Engineer in Hydro Québec, Montréal, Canada. He mainly involved in planification, exploitation, equipment and distribution network. Since 1990, he is the coordinator of R\&D activities in the area of power quality. He has worked on many power quality problems of industrial clients. He is member of Ordre des Ingénieurs du Québec. 